\title{
Editorial
}

\section{A Call to Action to Develop Integrated Curricula in Cardiorenal Medicine}

\author{
Claudio Ronco $^{\mathrm{a}, \mathrm{b}}$ Federico Ronco ${ }^{c}$ Peter A. McCullough ${ }^{d}$ \\ ${ }^{a}$ Department of Nephrology, San Bortolo Hospital, and ${ }^{\mathrm{b}}$ International Renal Research Institute of Vicenza (IRRIV), \\ San Bortolo Hospital, Vicenza, and 'Interventional Cardiology, Ospedali Dell'angelo e SS Giovanni e Paolo, Venice, \\ Italy; ${ }^{d}$ Baylor University Medical Center, Baylor Heart and Vascular Hospital, Baylor Heart and Vascular Institute, \\ Dallas, TX, USA
}

\section{Keywords}

Cardiovascular disease - Chronic kidney disease - Acute kidney injury - Heart failure - Acute coronary syndrome . Dialysis - Renal replacement therapy · Education - Training

\begin{abstract}
With the adoption of the new definition and classification of cardiorenal syndrome (CRS) and its relevant subtypes, much attention has been placed on elucidating the mechanisms of heart and kidney interactions. Of great interest are the pathophysiological pathways by which acute heart failure may result in acute kidney injury (AKl; type 1), chronic heart failure accelerating the progression of chronic kidney disease (CKD; type 2), AKI provoking cardiac events (type 3), and CKD increasing the risk and severity of cardiovascular disease (type 4). A remarkable interest has also been placed on the acute and chronic systemic conditions, such as sepsis and diabetes, which simultaneously affect heart and kidney function (type 5). Furthermore, the physiology of acute and chronic heart-kidney cross talk is drawing attention to hemodynamics (fluids, pressures, flows, resistances, perfusion), physiochemical (electrolytes, $\mathrm{pH}$, and toxins), and biological (inflammation, immune system activation, neurohormonal signals) processes. Common clinical scenarios call for recognition, knowledge, and skill in managing CRS. There is a clear need for medical and surgical specialists that are well versed
\end{abstract}

\section{KARGER}

(C) 2017 S. Karger AG, Basel

E-Mail karger@karger.com

www.karger.com/bpu in the pathophysiology and the clinical manifestations that arise in the setting of CRS. With this editorial, we are making a call to action to stimulate universities, medical schools, and teaching hospitals to create a core curriculum for cardiorenal medicine to better equip the physicians of the future for these common, serious, and frequently fatal syndromes.

(c) 2017 S. Karger AG, Basel

\section{Introduction}

For many years increasing efforts have been made to manage patients with simultaneous heart and kidney dysfunction, as evidenced by a rising number of clinical investigations and publications concerning cardiorenal syndromes (CRS) [1,2]. Nevertheless, very little progress has been made in managing heart or kidney patients with specific attention to preserving the integrity of the cardiorenal axis and the surviving function of both organs $[3,4]$. For example, acute heart failure (AHF) patients often have a worsening renal function compared to during the course of intravenous diuretic treatment due to

On October 25, 2017, this Editorial will be published simultaneously in Blood Purification (Blood Purif 2017;44:251-259) and Reviews in Cardiovascular Medicine (Rev Cardiovasc Med 2017;18:93-100).
Claudio Ronco, MD

Department of Nephrology, Dialysis and Transplantation International Renal Research Institute of Vicenza (IRRIV) San Bortolo Hospital, Viale Rodolfi 37, IT-36100 Vicenza (Italy) E-Mail cronco@goldnet.it 
delayed plasma refill and possibly acute kidney injury (AKI) [5]. Whether the setting is AHF or any other hospitalized illness, studies suggest that AKI according to virtually any definition is associated with increased risks for prolonged hospitalization, a need for intensive care unit services, renal replacement therapy, progression of kidney disease, cardiovascular events, rehospitalization, and death [6]. In 2008, a systematic approach to heart and kidney interactions was published in the Journal of the American College of Cardiology [7] and immediately followed by a consensus statement of the European Heart Journal by the Acute Disease Quality Initiative in order to bring the issue of cardiorenal renal syndromes to a focal point among experts in cardiology, nephrology, and critical care [8].

The first step was to create and drive a consensus on definitions and classifications of CRS in common clinical scenarios with the recognition that the process of organ injury or dysfunction leading to the injury or dysfunction of the other organ could be in some circumstances relatively unidirectional, bidirectional, and interactive [9]. The consequent adoption of the new definition/classification of the CRS led to significant efforts to elucidate pathophysiological mechanisms and to describe the clinical consequences of each subtype [10]. Thus, specific features have been analyzed, such as AKI following AHF (type 1) [11], chronic kidney disease (CKD) induced by chronic heart failure (type 2) [12], acute myocardial dysfunction in the context of AKI (type 3) [13], and finally a high incidence of cardiovascular events in CKD and hemodialysis patients (type 4) [14]. A remarkable interest has also been placed on simultaneous, overwhelming systemic conditions causing the fulminant failure of both organs, for example in the setting of burns, sepsis, and rhabdomyolysis (type 5) [15].

A critical feature to most analyses has been the status of both intravascular and extravascular volume. A reasonable conclusion that appears to be generalizable in the setting of both acute and chronic CRS as compared to the normal state is that there is a narrowed therapeutic window for volume management. This means that a patient at risk for or with CRS experiences hazards of relative volume depletion, including hypotension and hypoperfusion. On the other end of the spectrum, there appears to be little tolerance for volume overload with consequences ranging from peripheral edema, which is nearly universal in hospitalized patients, to pulmonary edema and respiratory failure, resulting in the need for diuresis, mechanical ventilation, and death [16]. An important recent understanding is that the kidneys are exquisitely sen- sitive to this volume spectrum. Additionally, the kidneys are the most sensitive organ to hypotension and are more likely to sustain damage with hypotension than any other organ system [17]. While hypotension and volume depletion are well-recognized determinants of prerenal azotemia and AKI, it has been recently appreciated that volume overload can result in renal congestion and a similar manifestation of AKI. In terms of physiochemical stressors, it is becoming increasingly recognized that both the early detection and management of lactic acidosis, electrolyte disturbances, and organ toxicities, including nephrotoxic pharmacologic agents and iodinated contrast, can make meaningful differences in the outcomes of cardiorenal patients [18]. Finally, pathobiological mechanisms involving innate immunity, inflammation, and neurohormonal response have also been highlighted in the bidirectional nature of heart-kidney cross talk [19, 20]. For example, it is well recognized that in the setting of critical illness, even in the absence of hypotension or marked electrolyte disturbances, both the heart and the kidney can manifest evidence of damage with elevations of cardiac troponin and novel markers of AKI [21]. For each mechanism and its resultant clinical syndrome, specific knowledge and skills are required to avoid harmful interventions and to provide the optimal supportive therapy to enable recovery. The need is emerging for a specialist in cardiorenal medicine to offer optimal care to patients at greatest need. This is in order to reduce the burden of serious sequelae, including the need for dialysis, permanent disability due to heart or kidney impairment, and death.

With this editorial, we are making a call to action to stimulate universities, medical schools, and teaching hospitals to create a core curriculum for cardiorenal medicine, as has been done for critical care nephrology, cardiac critical care, and other disciplines that bridge the knowledge and skills between fields of cardiology and nephrology (Fig. 1) [22, 23].

\section{CRS Type 1}

This condition occurs across the entire spectrum of hemodynamic subsets of AHF [24]. Commonly, a relatively low cardiac output state or impaired forward perfusion are determinants of the rise in serum creatinine and blood urea nitrogen, and the reduction in urine output after intravenous diuretics [8]. On the other hand, effective perfusion to the kidneys could be impaired due to renal congestion, venous hypertension, and right ventric- 


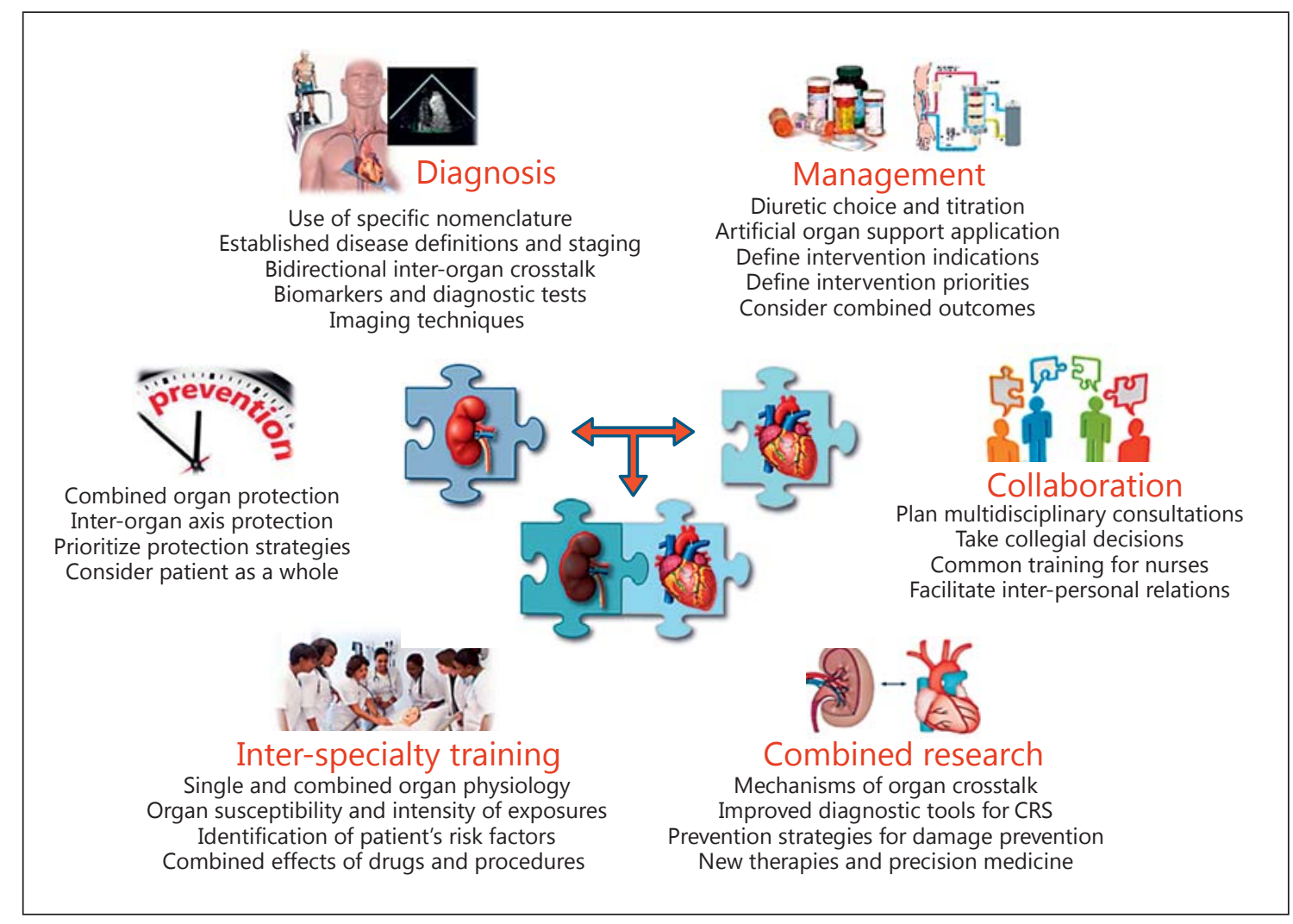

Fig. 1. Conditions and opportunities for common intervention and collaboration between cardiologists and nephrologists in patients with combined disorders of the heart and kidneys. The pieces of the puzzle may come together thanks to a combined effort of interdisciplinary training, common research, and strong commitment for collaboration. Multiple areas from pathophysiology to diagnosis, prevention, and treatment represent the ideal arena for this future exercise, hopefully leading to a true cardiorenal medicine.

ular dysfunction. Diastolic dysfunction and acute heart decompensation may represent additional risk factors and precipitating events leading to decreased kidney perfusion. The underlying pathophysiology is complex and involves oxidative stress and dysfunctional cell signaling; hence, there is hope for future therapies $[25,26]$. In this syndrome, there is a need for coordinating the balance between optimizing hemodynamics and decongesting the kidneys within an appropriate timeline [27]. The development of novel therapies has been hampered by "short termism" among pharmaceutical sponsors and investigators, with the uniform failure of agents given for just $48 \mathrm{~h} \mathrm{[28].} \mathrm{The} \mathrm{acute} \mathrm{and} \mathrm{extended} \mathrm{use} \mathrm{of} \mathrm{drugs} \mathrm{and}$ strategies should be considered as a way forward. A combined strategy should be undertaken to achieve organ function recovery and symptom relief with maintenance or improvement in renal filtration function. Concerted efforts by cardiologists, nephrologists, and critical care specialists are needed to identify specific phenotypes of CRS type 1, and then design management strategies for that phenotype to maximize both cardiac and renal outcomes [29].

\section{CRS Type 2}

Chronic heart failure is one of the most common cardiovascular conditions, with ischemic heart disease contributing to two-thirds of those with reduced LV function and to about half with preserved LV function [30]. The vast majority of patients have longstanding antecedent hypertension with ostensibly normal renal filtration function but subclinical kidney disease and an impaired renal functional reserve. This means that, in the setting of stress or load of any type, the kidneys have a reduced ability to adapt to and manage a filtered load of solute and are 
at risk of creating volume overload and azotemia [9]. Small episodes of acute decompensation or superimposed ischemic events may unveil a latent CKD and cause further damage in a highly susceptible kidney, leading to a rise in serum creatinine, proteinuria, and CKD progression [31]. In these patients, it is quintessential to coordinate a treatment that combines the clinical demand for neurohormonal modulation, maintenance of diuresis, control of blood pressure, management of potassium and the acid base, and maintenance of adequate body hydration. In particular, the use of diuretics and disease-modifying drugs for heart failure should be carefully titrated with a multidisciplinary approach based on the criteria of precision and personalized medicine.

\section{CRS Type 3}

For many years, AKI was considered an isolated entity to be managed with the intent of replacing renal function and maintaining the fluid and solute balance in patients at risk for severe pathophysiological derangements [32]. Today, AKI is perceived as a syndrome with evident consequences on distant organ function [10]. Among these, the renocardiac effects mediated though physical, chemical, and immunological signals may result in severe myocardial dysfunction [33]. Not only should the acid base and electrolyte be carefully managed, but also the fluid balance and blood pressure must be controlled in patients with AKI. In patients undergoing renal replacement therapy for severe oliguria and uremia, these tasks should be accomplished by different extracorporeal techniques whose prescription and delivery must be accurate and carefully executed using an accepted nomenclature [34]. The experience of the nephrologist is paramount in establishing the scope and goals of diuretic and extracorporeal therapy. The prescription and delivery of renal treatments should aim towards physiological targets covering the magnitude and timing of the desired changes in volume in relation to the response in right and left ventricular function. In this endeavor, the combined effort of the nephrologist with a cardiologist in the care of the critically ill patient will be the winning strategy.

\section{CRS Type 4}

The effects of CKD on the " 4 corners of cardiovascular disease," including atherosclerosis, myocardial disease, arrhythmias, and valvular disease, are well known [35].
Every CKD and end-stage renal disease (ESRD) patient is almost inevitably a cardiac patient with several issues to be considered [36]. From the point of view of the kidneys, the main task is the reduction of CKD progression through the control of intraglomerular hemodynamics and hyperfiltration, the limitation of protein and salt intake, neurohormonal modulation, and control of blood pressure [37]. Recent evidence has pointed out that chronic inflammation, anemia, and metabolic alterations typical of uremia (e.g., hyperuricemia) $[38,39]$ even at its early stages may influence the rate of vascular calcification, myocardial fibrosis, aortic and mitral calcification, and the propensity for atrial and ventricular arrhythmias $[40,41]$. In this syndrome, there appears to be opportunities to improve the micronutrient status of patients with the goal of reducing frailty and complications over time $[42,43]$. We suggest that every CKD patient should be regularly followed up by both a nephrologist and cardiologist with mutual interests in cardiorenal medicine [44]. Particular attention should be paid to the detection and management of asymptomatic left ventricular dysfunction, atrial fibrillation, and valvular disease with an eye on the risk for bacterial endocarditis $[45,46]$. Assessment of the functional classification is important for nephrologists working with ESRD patients in order to speak the same language as heart failure specialists [47]. The message is clear: CKD and ESRD are signals for cardiovascular care just as much as congenital heart disease, severe dyslipidemia, or a family history of premature cardiovascular disease are [48]. Additionally, there are considerable opportunities to collaborate on the mode of dialysis in order to optimize cardiovascular outcomes [49]. For example, patients appropriate selected for short daily home hemodialysis have been found to have significantly lower rates of heart failure hospitalizations, but this is balanced against higher risks of infection [50].

\section{CRS Type 5}

Simultaneous dysfunction of the heart and kidneys may result from systemic disorders such as sepsis from burns, or other fulminant syndromes [12]. These conditions may affect each organ through common mechanisms (e.g., endotoxin) but also through disease-associated or pathogen-associated molecular patterns [51, 52]. Specialists in the field of cardiology and nephrology may fruitfully collaborate to identify simultaneous cardiac and renal dysfunction in the setting of multiorgan system failure. Specialty-driven decisions may help to modify the 


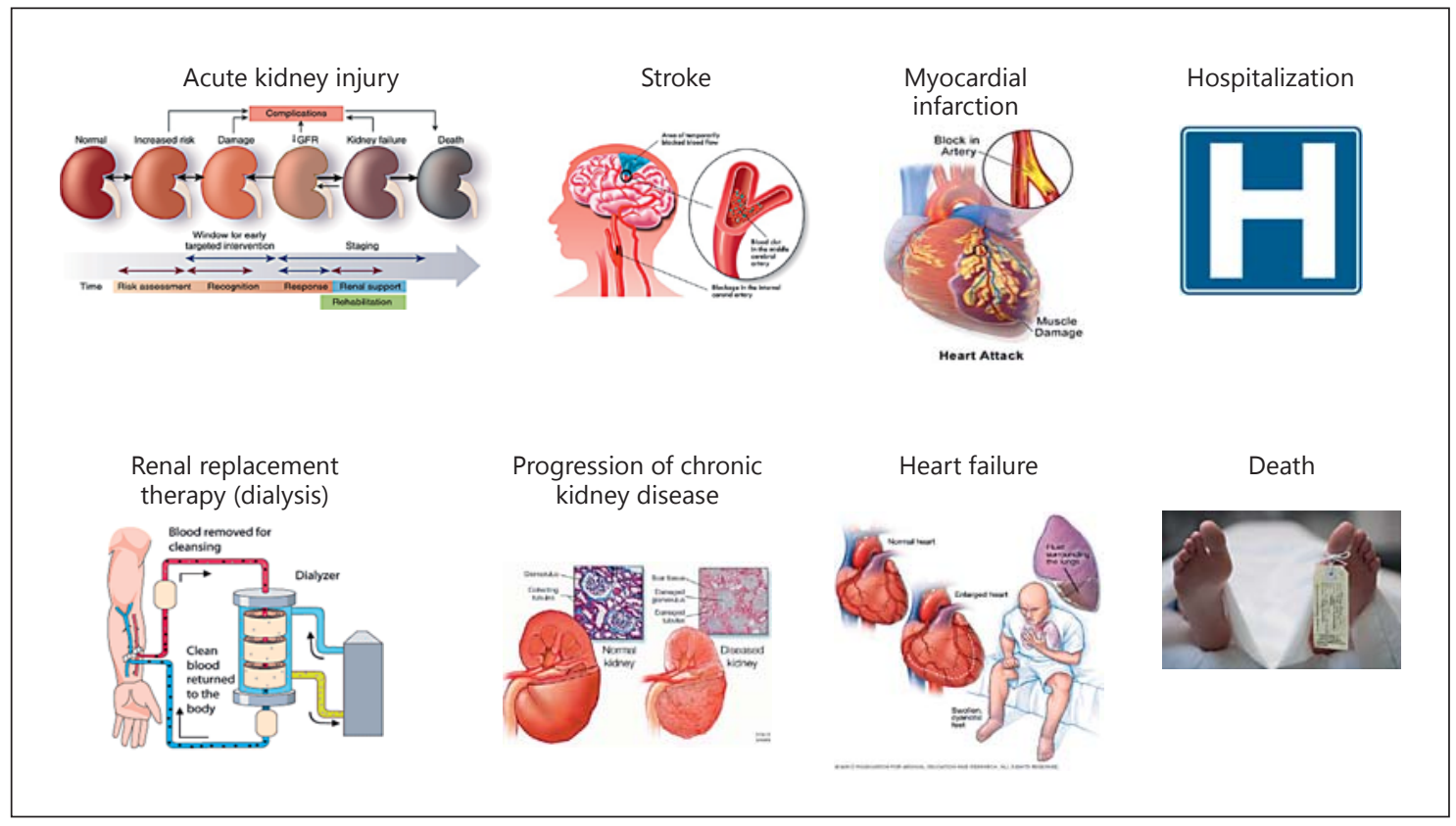

Fig. 2. Major adverse renal and cardiac events (MARCE) are strongly associated with AKI and raise the possibility of strategies that reduce AKI, translating into improved clinical outcomes as measured by the time to first MARCE event in clinical trials.

course or mitigate the effects of the main disease on the single organ, including inotropic support, renal replacement therapy, and extracorporeal oxygenation. The interpretation of laboratory testing and decisions to perform diagnostic procedures or specific therapies require the coordinated evaluation of each single case [53]. Optimal strategies defined for type 5 CRS will be paramount to improving the outcomes of these dire cases.

\section{Unmet Clinical Needs}

Heart and kidney interactions are bidirectional and time dependent [10]. It becomes evident from what has been described above that it is misleading and even dangerous to manage a single organ dysfunction without considering the secondary organ in the cardiorenal axis. It is worthless to consider the primary organ involvement and the origin of the syndrome without considering the vicious circle that may engage once both organs are affected.

Today, the cardiologist mainly manages cardiorenal syndromes type 1 and 2, while the nephrologist mainly treats types 3 and 4 . There are no concerted efforts for the prevention of CRS at the individual or institutional level

A Call to Action to Develop Integrated Curricula in Cardiorenal Medicine
[54]. Very little interaction is institutionally defined. Occasional interdisciplinary activity may take place on the basis of a consultation, but often comes too late in patient care [55]. There is no uniform utilization of novel biomarkers to phenotypically classify and manage patients $[53,56,57]$. A multidisciplinary combined approach to CRS is lacking and patients are suffering from partial or restricted care due to a narrow medical perspective of the primary specialty [58]. We are making a call to action for specialists of different disciplines, namely cardiology and nephrology, to collaborate and to share information and knowledge concerning the critically ill patient both at the bedside and in the classroom, in order to provide a platform for this increasingly ill and expanding population of patients [59].

\section{Educational Proposal}

We are making a special call for specialists from either field to work side by side to achieve optimal care for every given cardiorenal patient. The last 20 years have seen major changes in the practice of medicine. The perception and understanding of $\mathrm{AKI}$ and $\mathrm{CKD}$ as multipliers for cardiovascular risk has evolved significantly in recent

Blood Purif 2017;44:251-259 
years. At the same time, the understanding of the importance of preserving renal function and protecting the kidney during cardiac operations and acute cardiac events has also increased significantly (Fig. 2). A particularly striking development is the increase in common literature between cardiology and nephrology, with papers and books on CRS and heart/kidney-associated disorders. Initially sustained by passionate specialists interested in the cross-fertilization between the 2 fields, cardiorenal medicine is now a discipline whose time has come.

There have been barriers to collaboration. Historically, the customary training in cardiology never really focused on areas outside of heart disease. In fact, some institutions have branched their departments of cardiology out from internal medicine, further increasing the distance both clinically and intellectually between cardiologists and the other specialties. The same is true for nephrology, although a more comprehensive education has always been part of this specialty as a branch of internal medicine because of the impact of systemic disease on the kidneys [60]. Thus, physicians in post-graduate medical education were oriented to a specialty rather than to actual patient problems [60]. This sectorial education often resulted in a sort of adversarial "them and us" mentality. Thus, specialists are often consulted for a procedure (e.g., cardiac catheterization or initiation of dialysis) with little collaboration on addressing the cardiorenal health of the patient [61]. In addition, complex syndromes encompassing heart and kidney disorders require the application of complex knowledge and familiarity with hemodynamic assessment, the skilled use of the clinical laboratory, pharmacology, and the use of invasive procedures [62]. This "package" is seldom present in a single physician or practice. The result is that such specialists often clash and provide only a partial consultation and therapeutic strategies of limited vision, fueling the fire of antagonism rather than cooperation. A second cause for a delayed interdisciplinary collaboration may reside in the desire to maintain control of acute patients while chronic and hopeless patients are "left to the others." This may be different in a full-coverage social security system versus a private practice and insurance-based for-profit environment. The truth is that a combined path of diagnosis and care can only come from a multidisciplinary approach in which cardiologists and nephrologists cooperate mutually and respectfully. It might be true that one specialist has advanced knowledge and skills concerning certain pathophysiological disorders (e.g., acute coronary syndrome) while the other is an expert in a given therapy (e.g., hemodialysis). However, neither specialist is fully competent to manage a patient in which organ cross talk is continuous and even amplified by an ever-changing clinical profile. Control of patient care defines power within the medical structure for the individual physician and his or her practice or department. In the pursuit of higher standing in the medical community, specialists clash instead of cooperating. There are important and obvious clinical reasons for collaborative care. Patients with combined heart and renal failure are complex and difficult to manage, and the secondary dysfunction of one organ may affect the outcomes and results of treatments of the primary organ. This is the case in patients undergoing interventional procedures or cardiac surgery. In fact, the occurrence of AKI strongly influences the clinical course and often dominates outcomes (intensive care unit length of stay, general care, need of dialysis, rehospitalization, and death). An additional consideration is the need to allocate resources appropriately with recognition of terminal cases, where both the cardiologist and nephrologist can jointly convey a terminal prognosis to the patient and family members. A combined-care model of specialists might redefine the use of drugs such as inotropic agents, vasopressors, diuretics and renin angiotensin system inhibitors, anticoagulants, lipid-lowering therapy, and agents to modify electrolytes (bicarbonate, phosphate binders, calcium, etc.). New perspectives might be developed to help revise criteria for extracorporeal therapy and mechanical ultrafiltration in patients with CRS.

Common goals should be established for both organ protection and the prevention of CRS, while maximum attention and a combined effort should be given to maximize all chances for organ and patient recovery. There should be no financial penalties for those physicians who participate in paired consultation and comanagement [63].

This area undoubtedly needs an injection of focused attention, and effort should be incorporated in the structure of training and research, clinical application, and creativity [64]. We propose an innovative educational program to enhance the curriculums in both cardiology and nephrology training:

1. Nephrology fellows should spend at least 6 months in a cardiology department learning the approach to the cardiac patient and the point of view of the paired specialty, providing answers to problems that currently seem insoluble, including the management of heart failure, hemodynamic assessment, electrocardiography, and noninvasive imaging. Particular emphasis should be placed on the detection and management of 
arrhythmias as well as noninvasive imaging of the hemodialysis patient who is often remote from cardiovascular care.

2. Cardiology fellows who intend to take an active role in the management of patients with acute and chronic heart failure at high risk of developing CRS should spend at least 6 months in a nephrology department learning the indication, prescription, and modality of delivery of extracorporeal support therapies. The cardiology fellow should acquire competency on the indications, initiation, and delivery of continuous renal replacement therapy for the cardiac patient with kidney problems. For this purpose, a special training program should be identified and enforced [65].

3. It is desirable, in large institutions, to develop fully combined programs resulting in board certification in both cardiology and nephrology. Fellowship status in aligned organizations, such as the Cardiorenal Society of America, is encouraged [66].

4. All tertiary institutions should have a "task force" allocated to the combined management of CRS and seek quality improvement and research opportunities in cardiorenal medicine.

5. Large institutions should encourage cardiology and nephrology faculties to develop career focus areas in cardiorenal medicine, with research platforms in basic, translational, preclinical, and clinical studies. Par- ticipation and leadership in multidisciplinary courses, such as the annual Vicenza Critical Care Nephrology course, the Cardiorenal Society of America Annual Meeting, and the Acute Dialysis Quality Initiative series of meetings, should be strongly encouraged in cardiorenal faculties with support from department chairs $[48,67,68]$.

In conclusion, cardiologists and nephrologists should form a new union of cardiorenal medicine, as was the case many decades ago. This pivotal branch of internal medicine should deal with the most critically ill patients in our hospitals and clinics today. The only way to make this happen is with formal collaboration.

Our views may be criticized as being overly ambitious and out of proportion with the significance of renal disease in the cardiology world and vice versa. However, it is clear that renal disease is the most important predictor of cardiovascular outcomes in all areas of cardiology and that cardiovascular disease is the leading cause of death in kidney patients, therefore barriers to collaboration must be overcome. We need a new generation of cardiorenal physicians with an avant-garde approach to the screening, detection, diagnosis, prognosis, and management of CRS. With these enthusiastic words, we pledge our professional efforts in realizing these aspirations and call on each and every one of you to play a role in the evolution of this specialty.

\section{References}

1 Ronco C: Cardiorenal and reno-cardiac syndromes: clinical disorders in search of a systematic definition. Int J Artif Organs 2008;31: $1-2$.

2 McCullough PA, Kellum JA, Haase M, Müller C, Damman K, Murray PT, Cruz D, House AA, Schmidt-Ott KM, Vescovo G, Bagshaw SM, Hoste EA, Briguori C, Braam B, Chawla LS, Costanzo MR, Tumlin JA, Herzog CA, Mehta RL, Rabb H, Shaw AD, Singbartl K, Ronco C: Pathophysiology of the cardiorenal syndromes: executive summary from the eleventh consensus conference of the Acute Dialysis Quality Initiative (ADQI). Contrib Nephrol 2013;182:82-98.

3 Bongartz LG, Cramer MJ, Doevendans PA, Joles JA, Braam B: The severe cardio-renal syndrome: "Guyton revisited." Eur Heart J 2005;26:11-17.

4 McCullough PA: Cardiorenal syndromes: pathophysiology to prevention. Int J Nephrol 2010;2011:762590.

5 Liang KV, Williams AW, Greene EL, Redfield MM: Acute decompensated heart failure and the cardio-renal syndrome. Crit Care Med 2008;36(suppl):S75-S88.
6 Ronco C, House AA, Haapio M: Cardio-renal syndrome: refining the definition of a complex symbiosis gone wrong. Intensive Care Med 2008;34:957-962.

7 Ronco C, Haapio M, House AA, Anavekar N, Bellomo R: Cardiorenal syndrome. J Am Coll Cardiol 2008;52:1527-1539.

8 Ronco C, McCullough P, Anker SD, Anand I, Aspromonte N, Bagshaw SM, Bellomo R, Berl T, Bobek I, Cruz DN, Daliento L, Davenport A, Haapio M, Hillege H, House AA, Katz N, Maisel A, Mankad S, Zanco P, Mebazaa A, Palazzuoli A, Ronco F, Shaw A, Sheinfeld G, Soni S, Vescovo G, Zamperetti N, Ponikowski P; for the Acute Dialysis Quality Initiative (ADQI) consensus group (2009): Cardio-renal syndromes: report from the consensus conference of the Acute Dialysis Quality Initiative. Eur Heart J 2010;31:703-711.

9 Kelly KJ: Acute renal failure: much more than a kidney disease. Semin Nephrol 2006;26: 105-13.
10 McCullough PA, Ahmad A: Cardiorenal syndromes. World J Cardiol 2011;26;3:1-9.

11 Haase M, Müller C, Damman K, Murray PT, Kellum JA, Ronco C, McCullough PA: Pathogenesis of cardiorenal syndrome type 1 in acute decompensated heart failure: workgroup statements from the eleventh consensus conference of the Acute Dialysis Quality Initiative (ADQI). Contrib Nephrol 2013;182: 99-116.

12 Cruz DN, Schmidt-Ott KM, Vescovo G, House AA, Kellum JA, Ronco C, McCullough PA: Pathophysiology of cardiorenal syndrome type 2 in stable chronic heart failure: workgroup statements from the eleventh consensus conference of the Acute Dialysis Quality Initiative (ADQI). Contrib Nephrol 2013; 182:117-136.

13 Bagshaw SM, Hoste EA, Braam B, Briguori C, Kellum JA, McCullough PA, Ronco C: Cardiorenal syndrome type 3: pathophysiologic and epidemiologic considerations. Contrib Nephrol 2013;182:137-157.
A Call to Action to Develop Integrated

Curricula in Cardiorenal Medicine
Blood Purif 2017;44:251-259 DOI: $10.1159 / 000480318$ 
14 Tumlin JA, Costanzo MR, Chawla LS, Herzog CA, Kellum JA, McCullough PA, Ronco C: Cardiorenal syndrome type 4: insights on clinical presentation and pathophysiology from the eleventh consensus conference of the Acute Dialysis Quality Initiative (ADQI). Contrib Nephrol 2013;182:158-173.

15 Mehta RL, Rabb H, Shaw AD, Singbartl K, Ronco C, McCullough PA, Kellum JA: Cardiorenal syndrome type 5: clinical presentation, pathophysiology and management strategies from the eleventh consensus conference of the Acute Dialysis Quality Initiative (ADQI). Contrib Nephrol 2013;182:174-194.

16 Husain-Syed F, McCullough PA, Birk HW, Renker M, Brocca A, Seeger W, Ronco C: Cardio-pulmonary-renal interactions: a multidisciplinary approach. J Am Coll Cardiol 2015;65:2433-2448.

17 Zhang J, Bottiglieri T, McCullough PA: The central role of endothelial dysfunction in cardiorenal syndrome. Cardiorenal Med 2017;7: 104-117.

18 McCullough PA, Choi JP, Feghali GA, Schussler JM, Stoler RM, Vallabahn RC, Mehta A: Contrast-induced acute kidney injury. J Am Coll Cardiol 2016;68:1465-1473.

19 Ronco C, Cicoira M, McCullough PA: Cardiorenal syndrome type 1: pathophysiological crosstalk leading to combined heart and kidney dysfunction in the setting of acutely decompensated heart failure. J Am Coll Cardiol 2012;60:1031-1042.

20 Virzì GM, Clementi A, Brocca A, de Cal M, Ronco C: Molecular and genetic mechanisms involved in the pathogenesis of cardiorenal cross talk. Pathobiology 2016;83:201-210.

21 Virzì GM, Clementi A, Brocca A, de Cal M, Marcante S, Ronco C: Cardiorenal syndrome type 5 in sepsis: role of endotoxin in cell death pathways and inflammation. Kidney Blood Press Res 2016;41:1008-1015.

22 Ronco C: The cardiorenal syndrome: basis and common ground for a multidisciplinary patient-oriented therapy. Cardiorenal Med 2011;1:3-4.

23 Ricci Z, Di Nardo M, Ronco C: Year in review 2013: Critical Care - nephrology. Crit Care 2014; 18:574.

24 Ismail Y, Kasmikha Z, Green HL, McCullough PA: Cardio-renal syndrome type 1: epidemiology, pathophysiology, and treatment. Semin Nephrol 2012;32:18-25.

25 Pastori S, Virzì GM, Brocca A, de Cal M, Clementi A, Vescovo G, Ronco C: Cardiorenal syndrome type 1: a defective regulation of monocyte apoptosis induced by proinflammatory and proapoptotic factors. Cardiorenal Med 2015;5:105-115.

26 Virzì GM, Clementi A, de Cal M, Brocca A, Day S, Pastori S, Bolin C, Vescovo G, Ronco C: Oxidative stress: dual pathway induction in cardiorenal syndrome type 1, pathogenesis. Oxid Med Cell Longev 2015;2015:391790.
27 Virzì GM, Clementi A, Brocca A, de Cal M, Vescovo G, Granata A, Ronco C: The hemodynamic and nonhemodynamic crosstalk in cardiorenal syndrome type 1. Cardiorenal Med 2014;4:103-112.

28 McCullough PA: How trialists and pharmaceutical sponsors have failed us by thinking that acute heart failure is a 48-hour illness. Am J Cardiol 2017;120:505-508.

29 Palazzuoli A, McCullough PA, Ronco C, Nuti R: Kidney disease in heart failure: the importance of novel biomarkers for type 1 cardiorenal syndrome detection. Intern Emerg Med 2015; 10:543-554.

30 McCullough PA, Khandelwal AK, McKinnon JE, Shenkman HJ, Pampati V, Nori D, Sullivan RA, Sandberg KR, Kaatz S: Outcomes and prognostic factors of systolic as compared with diastolic heart failure in urban America. Congest Heart Fail 2005;11:6-11.

31 Sawhney S, Marks A, Fluck N, Levin A, Prescott G, Black C: Intermediate and longterm outcomes of survivors of acute kidney injury episodes: a large population-based cohort study. Am J Kidney Dis 2017;69:18-28.

32 Ronco C: Continuous renal replacement therapies for the treatment of acute renal failure in intensive care patients. Clin Nephrol 1993; 40:187-198.

33 Clementi A, Virzì GM, Brocca A, de Cal M, Pastori S, Clementi M, Granata A, Vescovo G, Ronco C: Advances in the pathogenesis of cardiorenal syndrome type 3. Oxid Med Cell Longev 2015;2015:148082.

34 Neri M, Villa G, Garzotto F, Bagshaw S, Bellomo R, Cerda J, Ferrari F, Guggia S, Joannidis M, Kellum J, Kim JC, Mehta RL, Ricci Z, Trevisani A, Marafon S, Clark WR, Vincent JL, Ronco C; Nomenclature Standardization Initiative (NSI) Alliance: Nomenclature for renal replacement therapy in acute kidney injury: basic principles. Crit Care 2016;20:318.

35 Herzog CA, Asinger RW, Berger AK, Charytan DM, Díez J, Hart RG, Eckardt KU, Kasiske BL, McCullough PA, Passman RS, DeLoach SS, Pun PH, Ritz E: Cardiovascular disease in chronic kidney disease: a clinical update from Kidney Disease: Improving Global Outcomes (KDIGO). Kidney Int 2011; 80:572-586.

36 McCullough PA, Steigerwalt S, Tolia K, Chen SC, Li S, Norris KC, Whaley-Connell A; KEEP Investigators: Cardiovascular disease in chronic kidney disease: data from the Kidney Early Evaluation Program (KEEP). Curr Diab Rep 2011;11:47-55.

37 Khouri Y, Steigerwalt SP, Alsamara M, McCullough PA: What is the ideal blood pressure goal for patients with stage III or higher chronic kidney disease? Curr Cardiol Rep 2011;13:492-501.

38 Palazzuoli A, Ruocco G, Pellegrini M, Beltrami M, Giordano N, Nuti R, McCullough PA: Prognostic significance of hyperuricemia in patients with acute heart failure. Am J Cardiol 2016;117:1616-1621.
39 Palazzuoli A, Ruocco G, De Vivo O, Nuti R, McCullough PA: Prevalence of hyperuricemia in patients with acute heart failure with either reduced or preserved ejection fraction. Am J Cardiol 2017, DOI: 10.1016/j.amjcard.2017.06.057.

40 Charytan DM, Fishbane S, Malyszko J, McCullough PA, Goldsmith D: Cardiorenal syndrome and the role of the bone-mineral axis and anemia. Am J Kidney Dis 2015;66:196205.

41 Hundae A, McCullough PA: Cardiac and renal fibrosis in chronic cardiorenal syndromes. Nephron Clin Pract 2014;127:106-112.

42 McCullough PA: Micronutrients and cardiorenal disease: insights into novel assessments and treatment. Blood Purif 2011;31:177-185.

43 Marinescu V, McCullough PA: Nutritional and micronutrient determinants of idiopathic dilated cardiomyopathy: diagnostic and therapeutic implications. Expert Rev Cardiovasc Ther 2011;9:1161-1170.

44 Dumler F, McCullough PA: Optimal dialysis for the end-stage renal disease patient with cardiovascular disease. Adv Chronic Kidney Dis 2004;11:261-273.

45 McCullough PA: Scope of cardiovascular complications in patients with kidney disease. Ethn Dis 2002;12:S3-S48.

46 McCullough PA: Opportunities for improvement in the cardiovascular care of patients with end-stage renal disease. Adv Chronic Kidney Dis 2004;11:294-303.

47 Chawla LS, Herzog CA, Costanzo MR, Tumlin J, Kellum JA, McCullough PA, Ronco C; ADQI XI Workgroup: Proposal for a functional classification system of heart failure in patients with end-stage renal disease: proceedings of the Acute Dialysis Quality Initiative (ADQI) XI Workgroup. J Am Coll Cardiol 2014;63:1246-1252.

48 McCullough PA: Cardiovascular disease in chronic kidney disease from a cardiologist's perspective. Curr Opin Nephrol Hypertens 2004; 13:591-600

49 McCullough PA, Chan CT, Weinhandl ED, Burkart JM, Bakris GL: Intensive hemodialysis, left ventricular hypertrophy, and cardiovascular disease. Am J Kidney Dis 2016; 68(S1):S5-S14

50 Morfin JA, Fluck RJ, Weinhandl ED, Kansal S, McCullough PA, Komenda P: Intensive hemodialysis and treatment complications and tolerability. Am J Kidney Dis 2016; 68(S1):S43-S50.

51 Virzì GM, Clementi A, Brocca A, de Cal M, Marcante S, Ronco C: Cardiorenal syndrome type 5 in sepsis: role of endotoxin in cell death pathways and inflammation. Kidney Blood Press Res 2016;41:1008-1015.

52 Brocca A, Virzì GM, Pasqualin C, Pastori S, Marcante S, de Cal M, Ronco C: Cardiorenal syndrome type 5 : in vitro cytotoxicity effects on renal tubular cells and inflammatory profile. Anal Cell Pathol 2015;2015:469461. 
53 McCullough PA, Bouchard J, Waikar SS, Siew $\mathrm{ED}$, Endre ZH, Goldstein SL, Koyner JL, Macedo E, Doi K, Di Somma S, Lewington A, Thadhani R, Chakravarthi R, Ice C, Okusa MD, Duranteau J, Doran P, Yang L, Jaber BL, Meehan S, Kellum JA, Haase M, Murray PT, Cruz D, Maisel A, Bagshaw SM, Chawla LS, Mehta RL, Shaw AD, Ronco C: Implementation of novel biomarkers in the diagnosis, prognosis, and management of acute kidney injury: executive summary from the tenth consensus conference of the Acute Dialysis Quality Initiative (ADQI). Contrib Nephrol 2013; 182:5-12.

54 McCullough PA: Prevention of cardiorenal syndromes. Contrib Nephrol 2010;165:101111.

55 Soares DM, Pessanha JF, Sharma A, Brocca A, Ronco C: Delayed nephrology consultation and high mortality on acute kidney injury: a meta-analysis. Blood Purif 2017;43:57-67.

56 Vasudevan A, Jazi HH, Won JI, Ball T, Patankar GR, Sarmast SA, Shin HJ, McCullough PA: Personalized treatment of heart failure with biomarker guidance using a novel disease severity score. Proc Bayl Univ Med Cent 2017;30:139-142.
57 Vasudevan A, Singer AJ, DeFilippi C, Headden G, Schussler JM, Daniels LB, Reed M, Than MP, Birkhahn R, Smith SW, Barrett TW, Arnold W, Peacock WF, McCullough PA: Renal function and scaled troponin in patients presenting to the emergency department with symptoms of myocardial infarction. Am J Nephrol 2017;45:304-309.

58 Rizo-Topete L, Ronco C: Critical care nephrology: a multidisciplinary approach. Blood Purif 2017;43:53-56.

59 Ronco C: The cardiorenal syndrome: basis and common ground for a multidisciplinary patient-oriented therapy. Cardiorenal Med 2011;1:3-4.

60 Agrawal V, Agarwal M, Ghosh AK, Barnes MA, McCullough PA: Identification and management of chronic kidney disease complications by internal medicine residents: a national survey. Am J Ther 2011;18:e40-e47.

61 Agrawal V, Ghosh AK, Barnes MA, McCullough PA: Perception of indications for nephrology referral among internal medicine residents: a national online survey. Clin J Am Soc Nephrol 2009;4:323-328.
62 Agrawal V, Ghosh AK, Barnes MA, McCullough PA: Awareness and knowledge of clinical practice guidelines for CKD among internal medicine residents: a national online survey. Am J Kidney Dis 2008;52:1061-1069.

63 McCullough PA: Cardiorenal intersection: crossroads to the future. Arq Bras Cardiol 2007;88:117-126

64 Agrawal V, Barnes MA, Ghosh AK, McCullough PA: Questionnaire instrument to assess knowledge of chronic kidney disease clinical practice guidelines among internal medicine residents. J Eval Clin Pract 2009;15: 733-738.

65 Costanzo MR, Chawla LS, Tumlin JA, Herzog CA, McCullough PA, Kellum JA, Ronco C: The role of early and sufficient isolated venovenous ultrafiltration in heart failure patients with pulmonary and systemic congestion. Rev Cardiovasc Med 2013;14:e123-e133.

66 Cardio Renal Society of America: http://www. cardiorenalsociety.org/.

67 International Renal Research Institute of $\mathrm{Vi}$ cenza: http://www.irriv.com/.

68 Acute Dialysis Quality Initiative: http://www. adqi.org/WhatIsADQI-Call.htm.
A Call to Action to Develop Integrated Curricula in Cardiorenal Medicine
Blood Purif 2017;44:251-259 DOI: $10.1159 / 000480318$ 